\title{
TRANSFORMATION OF STRUCTURAL COMPONENTS OF MASTICATORY MUSCLES OF IMMATURE ANIMALS IN DIFFERENT STAGES OF MERCAZOLILUM-INDUCED HYPOTHYROIDISM
}

\author{
Nazar Sahan \\ Department of Human Anatomy \\ Ivano-Frankivsk National Medical University \\ 2 Halytska str., Ivano-Frankivsk, Ukraine, 76018
}

\begin{abstract}
The aim of the study. The aim of this study was to establish the features of the structural organization of the chewing and lateral pterygoid muscles of immature rats during the developmental stages of experimental hypothyroidism.

Materials and methods. The material for the study was the chewing and lateral pterygoid muscles of 48 white mongrel immature rats-males. The following research methods were used: mercazole-induced hypothyroidism modelling, injection method for studying the bloodstream, histological examination of blood vessels and tissue elements, electron microscopy, morphometric analysis, biochemical methods, statistical evaluation of the results.

Results. A violation of thyroid homeostasis (a decrease in the concentration of thyroid hormones in the blood) has been established. In the bloodstream, edematous changes are observed histologically and submicroscopically. A decrease in the number of hemocapillaries per unit area and the number of hemocapillaries per muscle fiber have been established morphometrically. In muscle fibers, cross striation with vacuolization of endomysia and perimisia is lost. Edematous changes are observed, which are aggravated depending on the duration of experimental hypothyroidism. The glycolytic muscle fibers are more affected, and the changes are aggravated depending on the duration of the experiment. It has also been found out that there is a redistribution in the amount of muscle fibers. There is a tendency to a decrease in oxidative-glycolytic and a significant increase in glycolytic muscle fibers.

The morphological changes that have been found out are accompanied by violations of the macroelement balance, in particular, the content of $\mathrm{Ca}, \mathrm{P}, \mathrm{Mg}$, which determine the functioning of skeletal muscle tissue.

Conclusion. Thus, at different periods of hypothyroidism, edematous changes occur both in the vascular wall and in muscle fibers, which are aggravated depending on the duration of hypothyroidism and are caused by a decrease in the basic metabolic rate, slowing of redox processes and tissue hypoxia. At the same time, chromotropic substances are released from bonds with proteins and accumulate in the intermediate substance with the subsequent replacement of collagen fibers by mucus-like masses.
\end{abstract}

Keywords: chewing muscles, muscle fibers, blood vessels, links of the hemomicrocirculatory bed, hypothyroidism, ontogenesis.

\section{Introduction}

Hypothyroidism at present is a fairly common disease and is associated with the prolonged, persistent deficiency of thyroid hormones in the body or with a deficiency of their biological effects at the tissue level $[1,2]$. According to many scientists, hypothyroidism leads to changes in almost all organs and tissues $[3,4]$. This is especially true in the process of development and formation of the organism $[5,6]$.

It should be noted that in our available biomedical literature today there was no work where the morphology of chewing muscles in hypothyroidism would be studied, while it is known that the functioning of masticatory muscles determines the state of the tooth-jaw system, digestive organs and other systems of the body $[7,8]$.

\section{Aim of the research}

Determine the peculiarities of the structural organization of masseter and lateral pterygoid muscles of immature rats at the stages of the development of experimentally modeled hypothyroidism. 


\section{Materials and methods}

The material for the study was masseter and lateral pterygoid muscle of 48 white outbred immature male rats. The material was taken in well-defined symmetrical places of masseter and lateral pterygoid muscles. Animals were divided into groups: group I - intact (12) animals, which were kept under normal vivarium conditions, with natural for rodent feed; group II - under conditions of mercazolilum-induced hypothyroidism (36 animals). Euthanasia of animals was performed by intraperitoneal administration of sodium thiopental ( $2 \%$ solution of sodium thiopental in a dose of $25 \mathrm{mg} / \mathrm{kg}$ of mass).

The following research methods were used: modeling of mercazolilum-induced hypothyroidism $[9,10]$; injection method of the study of the masticatory muscles' bloodstream; histological examination of blood vessels and tissue elements of the masticatory muscles (staining with hematoxylin and eosin, fuchsin according to Hart, trichrome staining according to Masson, hematoxylin-basic fuchsine-picric acid according to Van Gieson; the histochemical method of masticatory muscles' study (succinate dehydrogenase (SDG) according to the method of M. Nachlas); electronic microscopic examination; morphometric analysis (mean value of blood vessels' lumen and their wall thickness, number of capillaries in $1 \mu \mathrm{m}^{2}$ cross-section of muscular fiber, amount of capillaries at one muscular fiber, the percentage of oxidation (OMF), oxidation-glycolytic (OGMF) glycolytic (GMF) muscular fibers, the average size of muscular fiber, biochemical methods, statistical analysis. The absolute amount of the muscle fibers of different phenotypes has been counted on transverse sections of muscle fibers in the conducting of a reaction of succinate dehydrogenase according to Nakhlas [11].

For biochemical studies, animals were decapitated in anesthetized conditions ( $2 \%$ sodium thiopental solution at a dose of $25 \mathrm{mg} / \mathrm{kg}$ of animal) and blood samples were taken with the usage of the heparin as an anticoagulant. The level of TSH, T3, and T4 in the rats' blood was defined by the method of enzyme-linked immuno sorbent assay [12], $\mathrm{Ca}, \mathrm{Mg}, \mathrm{P}$ by the atomic absorption spectroscopy on spectrophotometer C-115PC [13].

The statistical processing of the results was carried out using a package Stat. Soft.Inc; Tulsa OK USA; Statistica 6.

\section{Results}

Thyroid homeostasis in the dynamics of the development of induced hypothyroidism in immature animals: during the $14^{\text {th }}$ day of TSH $-0.21 \pm 0.02 \mu \mathrm{M} / \mathrm{ml}(\mathrm{p}<0.01), \mathrm{T}_{3}-3.11 \pm 0.37 \mu \mathrm{M} / \mathrm{ml}$ $(\mathrm{p}<0,01), \mathrm{T}_{4}-37.98 \pm 3.42(\mathrm{p}<0.01) \mathrm{mM} / \mathrm{ml}$. During the $21^{\text {st }}$ day of the development of hypothyroidism, the indicators were: TSH $-0.14 \pm 0.01 \mu \mathrm{M} / \mathrm{ml}(\mathrm{p}<0.01), \mathrm{T}_{3}-3.81 \pm 0.44 \mu \mathrm{M} / \mathrm{ml}(\mathrm{p}<0.01)$, $\mathrm{T}_{4}-52.97 \pm 6.85(\mathrm{p}<0.01) \mu \mathrm{M} / \mathrm{ml}$. During the $28^{\text {th }}$ day, the thyroid status was: $\mathrm{TSH}-0.12 \pm 0.01 \mu \mathrm{M} / \mathrm{ml}$ $(\mathrm{p}<0.01), \mathrm{T}_{3}-3.68 \pm 0.34 \mu \mathrm{M} / \mathrm{ml}(\mathrm{p}<0.01), \mathrm{T}_{4}-53.57 \pm 6.06(\mathrm{p}<0.01) \mu \mathrm{M} / \mathrm{ml}$.

During the study of the vascular bed of masticatory muscles of immature animals during the $14^{\text {th }}$ day of mercazolilum-induced hypothyroidism, there was determined that the intramuscular vasculature, as well as endomysium and perimysium, are characterized by deformed sockets and loops, as well as the alternation of narrowed and expanded areas (Fig. 1). The morphometric study showed a significant decrease in the diameter of the arterial bed and a significant thickening of the vascular wall. In the venules and veins of the endomysium and perimysium we've determined an increase in diameter and some thinning of the wall, as compared to the norm, both in the masseter and in the lateral pterygoid muscles. These changes are confirmed histologically. During the study of hemocapillaries there is a decrease of their number as compared with the norm (Fig. 2, 3).

During the electronic microscopic examination, endothelial cells with cytoplasm of reduced electron density could be noted (Fig. 4). Their nuclei are light, the nuclear membrane is invaginated. The granular endoplasmic reticulum consists of the expanded tubules and cisterns with low electron density. Vesicles and tubules of the Golgi apparatus are expanded. Mitochondria are enlarged, containing a matrix of low electron density, mitochondrial crests have obscure contours. In some of mitochondria the crests are deformed or even destroyed. There are many micropinocytotic vesicles in the cytoplasm. 


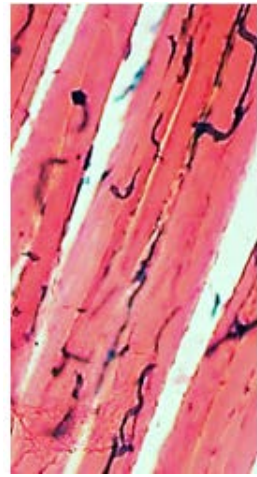

$a$

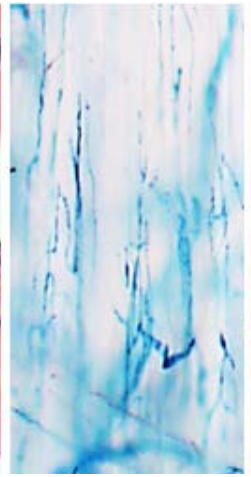

$b$

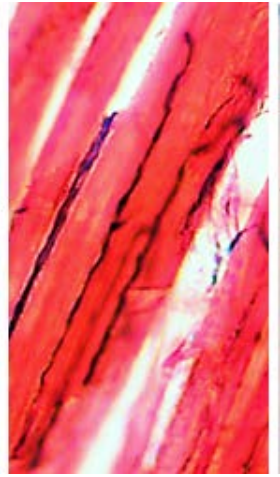

$c$

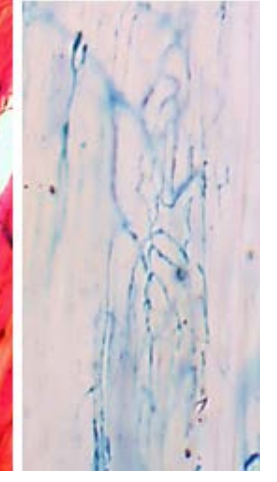

$d$

Fig. 1. Angioarchitectonics of the vascular bed of muscular fibers of the immature rats during the $14^{\text {th }}$ day of mercazolilum-induced hypothyroidism: $a$-deformation of vascular bed of the masseter muscle; $b$-desolation in the vessels of the masseter muscle; $c$-devastation and deformation of the vascular pattern; $d$ - uneven vascular filling in the lateral pterygoid muscle. Staining: $a, c$-injection with Parisian blue with additional staining of hematoxylinum and eosin; $b, d$ - injection with Parisian blue. Microphotograph. Magnification: ocular lens 10; field lens 20

Amount of capillaries

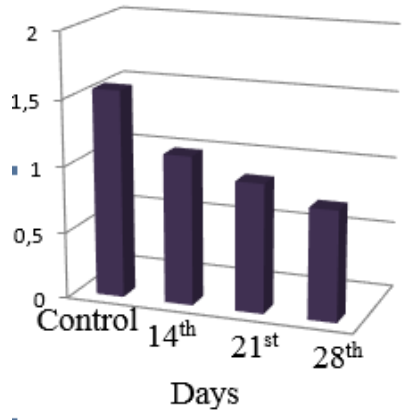

\section{Amount of capillaries}

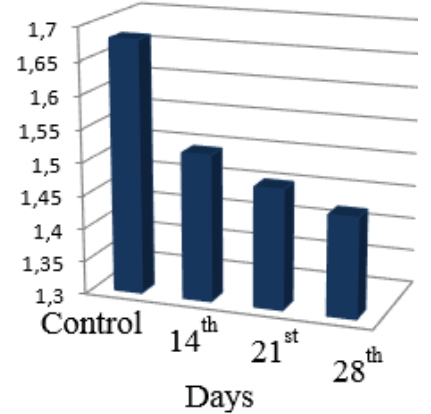

$b$

Fig. 2. Reduction of the number of hemocapillaries in $1 \mu \mathrm{m}^{2}$ in the masticatory muscles of immature animals at various stages of the development of mercazolilum-induced hypothyroidism: $a$ - reduction of the number of hemocapillaries per unit area in the masseter muscle; $b$ - reduction of the number of hemocapillaries per unit area in the lateral pterygoid muscle

In the muscles there were observed a change in cross-striation. Muscular fibers are of round shape with uneven contours on transverse sections (Fig. 5). Endo- and perimysium are significantly enlarged with edema and loose fibrous connective tissue structures (Fig. 6). 


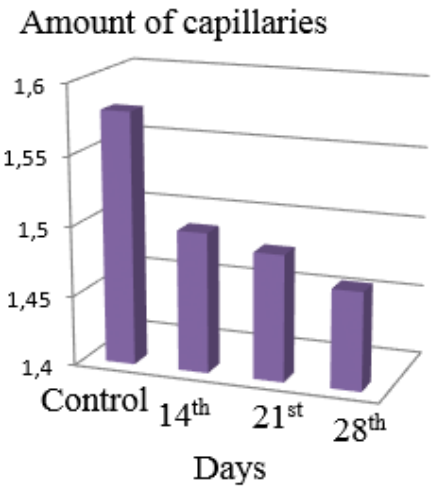

$a$

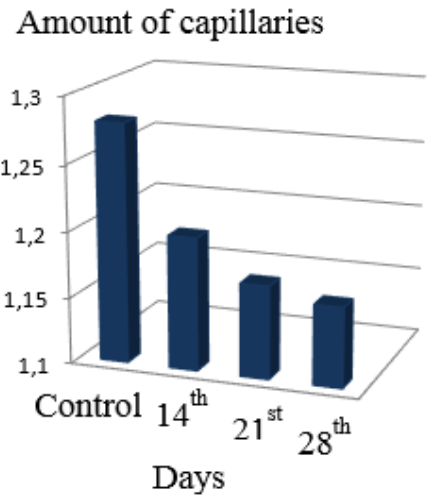

$b$

Fig. 3. Reduction of the number of hemocapillaries at one muscular fiber in the masticatory muscles of immature animals at various stages of the development of mercazolilum-induced hypothyroidism: $a$ - the reduction of the number of hemocapillaries pertaining to one muscular fiber in masseter muscle; $b$ - the reduction of the number of hemocapillaries per muscular fiber in the lateral pterygoid muscle

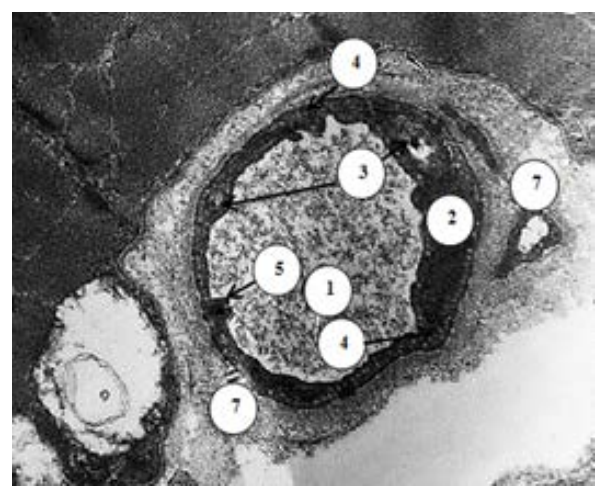

$a$

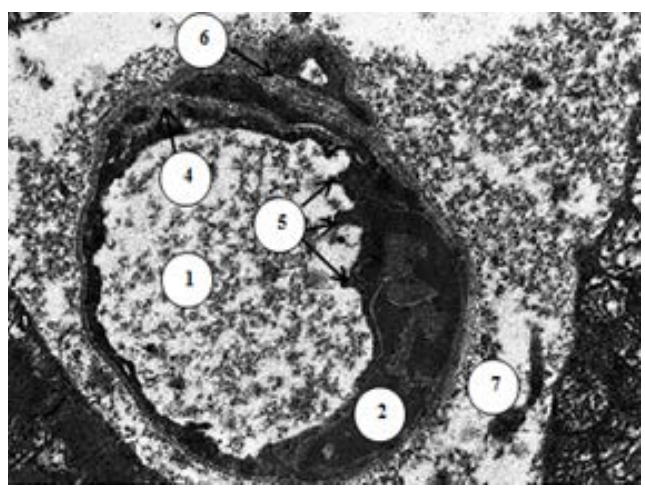

$b$

Fig. 4. Electronic microscopic changes in the structure of the hemocapillary of the masticatory muscles of immature rat during the $14^{\text {th }}$ day of the development of mercazolilum-induced hypothyroidism: $a$-hemocapillary of masseter muscle; $b$ - changes in the structure of the hemocapillary of the lateral pterygoid muscle. Electronic Microphotograph. Magnification: $a, b-8000$. Signs: 1 - lumen of hemocapillary, 2 - deformed nucleus of endothelial cell of hemocapillary, 3 - vacuolization of cytoplasm of endotheliocyte, 4 - pinocytic vesicles, 5 - microclasmatosis, 6 - loose fiber of basal membrane of hemocapillary, 7 - expanded and vacuolated perivascular space 


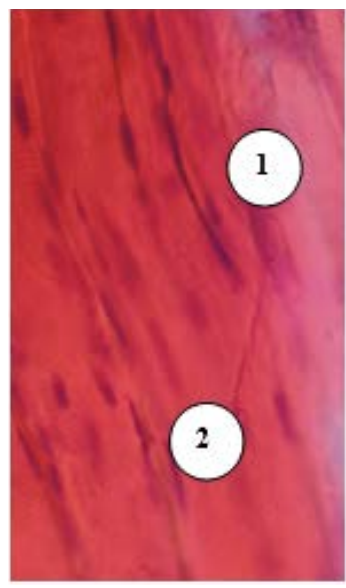

$a$

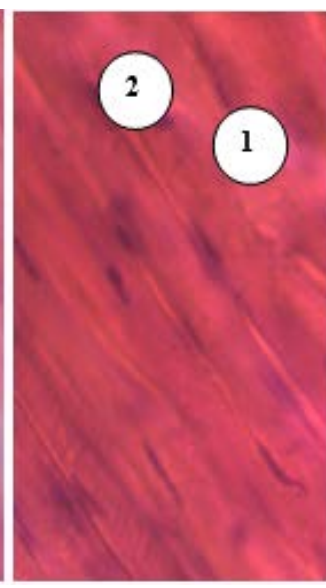

$b$

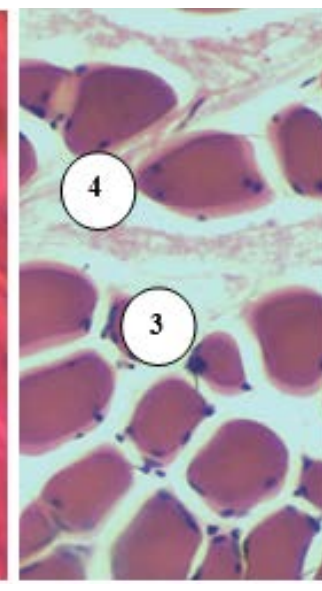

$c$

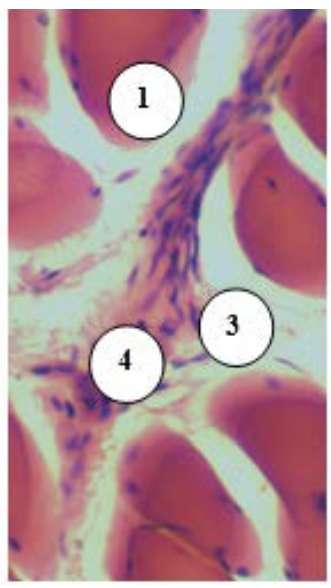

$d$

Fig. 5. Swelling of muscular fibers and connective tissue elements of endomysium of the masticatory muscles of immature rats during the $14^{\text {th }}$ day in the conditions of induced hypothyroidism: $a$-swollen muscular fibers of masseter muscle; $b$-swelling and loss of cross-striation in the lateral pterygoid muscle; $c$ - enlargement and edema of the endomysium of masseter muscle; $d$-separation of fibers of connective tissue elements of the endomysium in the lateral pterygoid muscle. Staining: hematoxylin and eosin. Microphotograph. Magnification: $a, b, c$ - ocular lens 10, field lens 40, d-ocular lens 10, field lens 20. Signs: 1 - muscular fiber edema, 2 - loss of cross-striation, 3 - expanded with signs of endomysium edema, 4 - loose fiber of connective tissue elements of endomysium
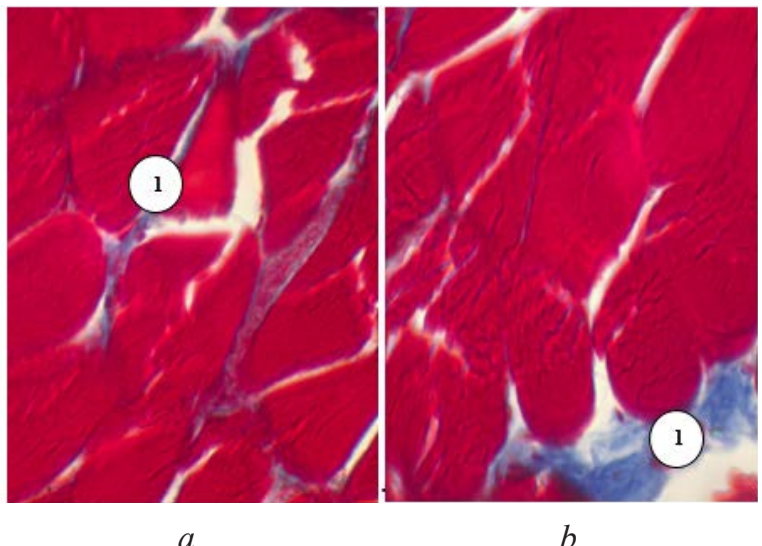

Fig. 6. Widening and edema of collagenous fibers of the endomysium of the masticatory muscles of immature rats during the $14^{\text {th }}$ day of the development of hypothyroidism: $a$ - swelling of endomysium in the masseter muscle; $b$-swelling and separation of fibers of endomysium in lateral pterygoid muscle. Staining, trichrome staining according to Masson. Microphotograph. Magnification: ocular lens 10, field lens 40. Signs: 1 - swollen loose fibers of connective tissue fibres of endomysium

In the study of SDG activity, there are observed some blurring and deformation of muscular fibers, increase and expansion of the intermucosal spaces (Fig. 7). One can note the reduction of OGMF. The number of OMF reduced. The amount of GMF increased significantly (Fig. 8). During the morphometric study, the cross-sectional area of all types of muscular fibers increases significantly (Fig. 9).

Electronically-microscopically, there were found edematous changes of all types of muscular fibers (Fig. 10). The least pronounced changes during the $14^{\text {th }}$ day of experimental hypothyroidism are observed during the ultrastructural study of OGMF. 


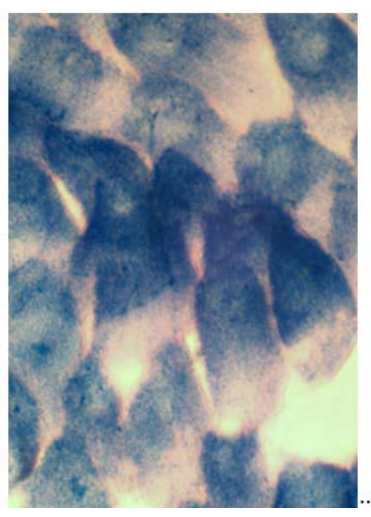

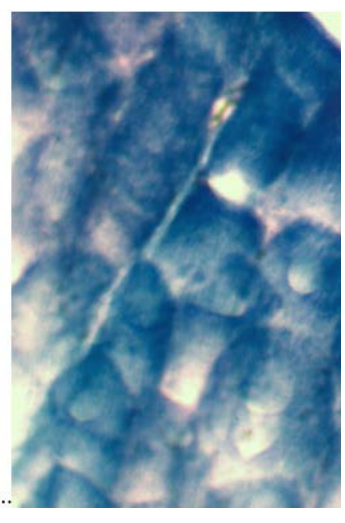

$b$

Fig. 7. Histochemical study of the masseter muscles of immature animals during the $14^{\text {th }}$ day of experimental hypothyroidism: $a$-swelling of muscular fibers in the masseter muscle;

$b$-swollen muscular fibers in the lateral pterygoid muscle. Staining: succinate dehydrogenase (SDG) according to M. Nachlas. Microphotograph. Magnification: $a, b$-ocular lens 10, field lens 40
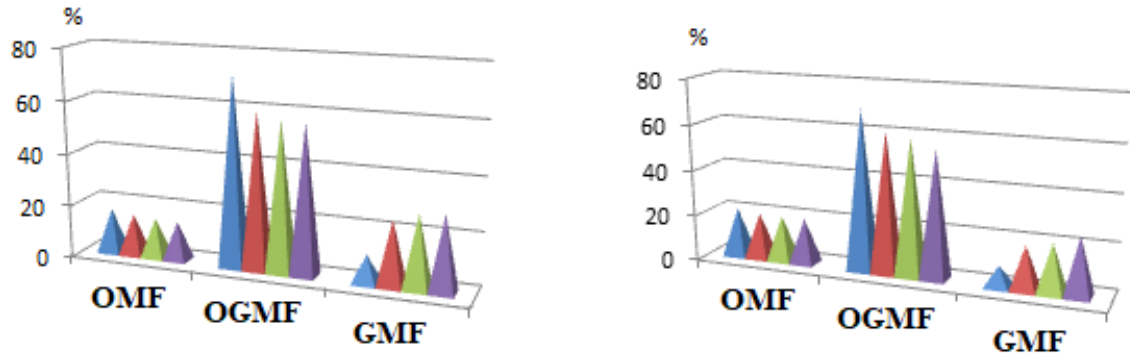

$\square$ Norm $\square 14^{\text {th }}$ day $\square 21^{\text {st }}$ day $\square 28^{\text {th }}$ day

$b$

Fig. 8. The change of the quantitative composition of muscular fibers in the masticatory muscles of immature animals in the norm and during different terms of experimental hypothyroidism: $a$ - the change in the quantitative composition of different types of fibers in the masseter muscle; $b$ - the change in the quantitative composition of different types of fibers in the lateral pterygoid muscle

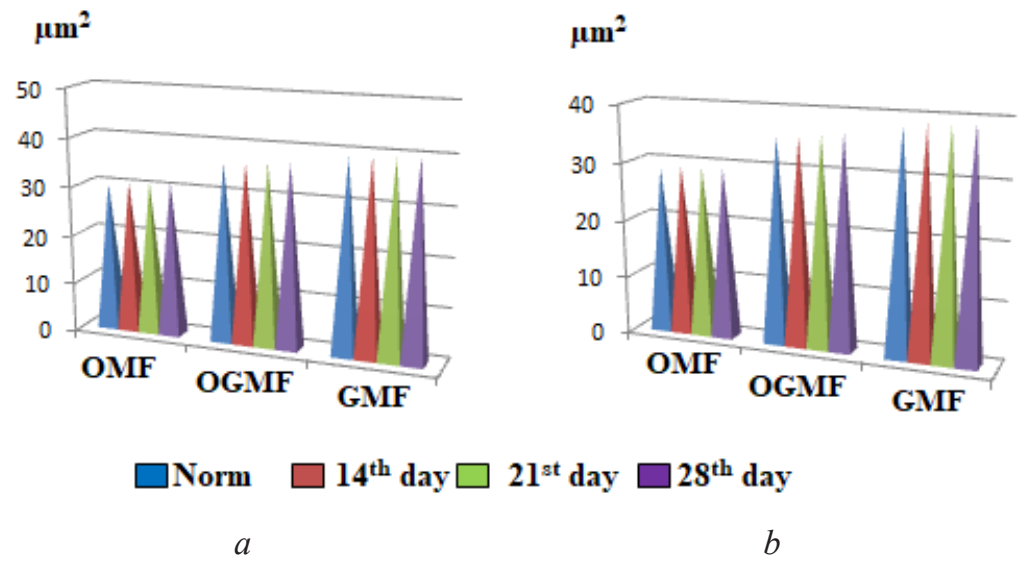

Fig. 9. Change of the cross-sectional area of muscular fibers of the masticatory muscles of immature animals in norm and during different periods of experimental hypothyroidism:

$a$-increase of the cross-sectional area of the muscular fibers in the masseter muscle; $b$ - increase of the cross-sectional area of muscular fibers in the lateral pterygoid muscle 
In this type of fibers there are some edematous changes with the expansion of the structural components of muscular triads, cisterns and tubules of the endoplasmic reticulum and vesicles and tubules of the Golgi apparatus, the lumenized mitochondrial matrix.

During the study of the vascular bed of masticatory muscles, during the $21^{\text {st }}$ day of the experiment, the deepening of the vascular pattern was found (Fig. 11). The injected vessels look uneven with the alternation of expanded and narrowed areas. During the histological study, there is a further decrease of the lumen of the arteries and the expansion of the veins of perimysium, endomysium and intramuscular arteries. At the same time, the thickening of the arterial wall and the significant dilation of the venous wall are observed.

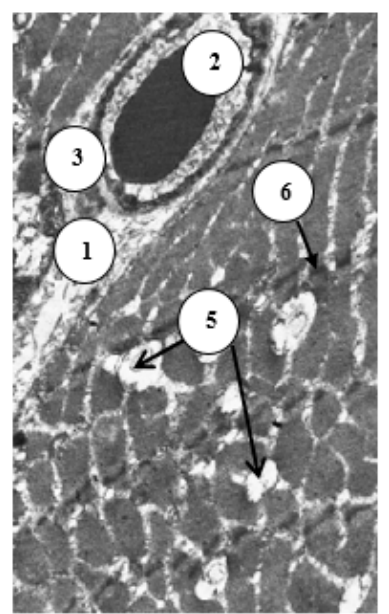

$a$

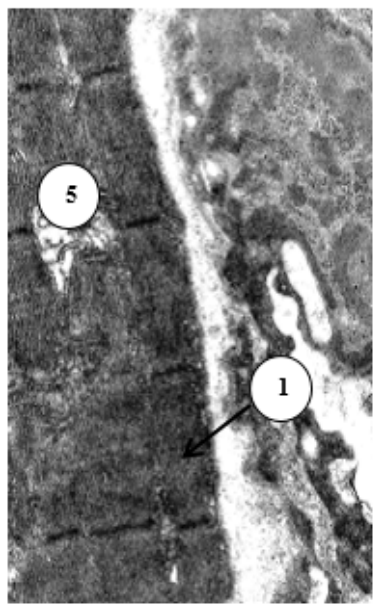

d

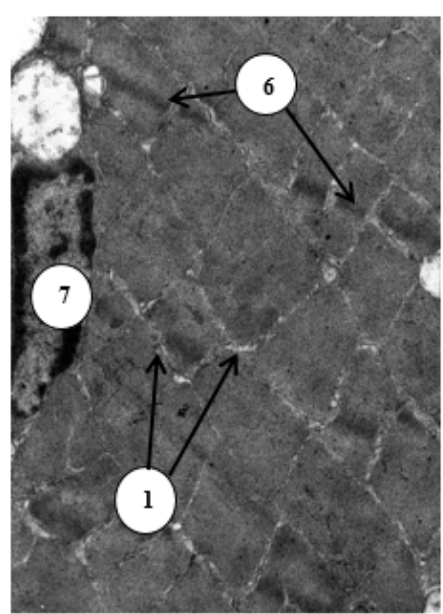

$b$

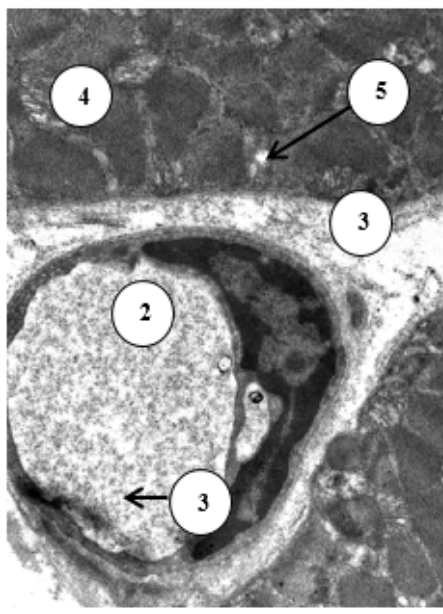

$e$

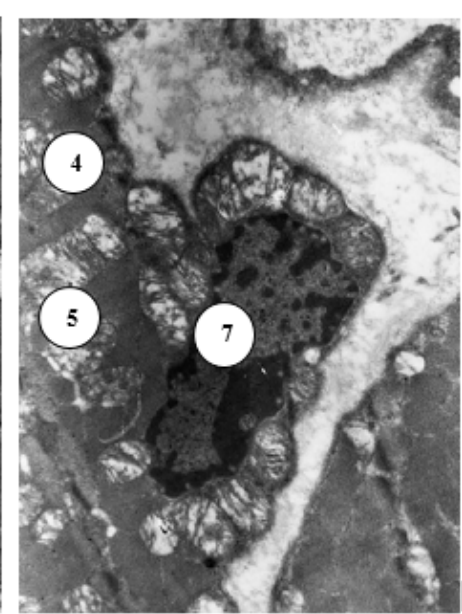

c

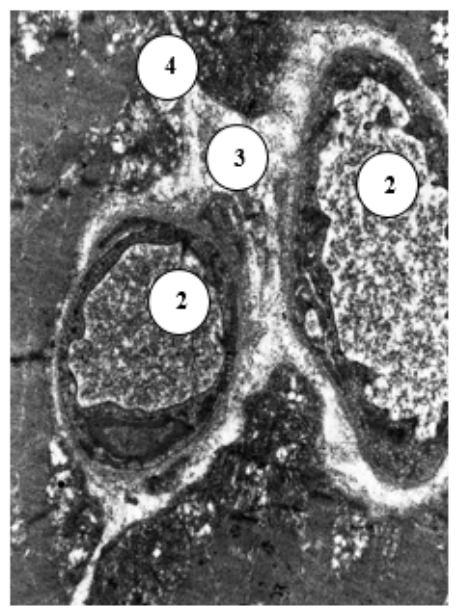

$f$

Fig. 10. Ultramicroscopic changes in the structure of the masticatory muscles of immature rat during the $14^{\text {th }}$ day of mercazolilum-induced hypothyroidism: $a$ - submicroscopic structure of GMF of masseter muscle; $b$ - electron microscopic characteristic of OGMF of masseter muscle; $c$-submicroscopic characteristic of OMF of masseter muscle; $d$-submicroscopic structure of GMF of the lateral pterygoid muscle; $e$ - electron microscopic characteristic of OGMF of lateral pterygoid muscle; $f$-submicroscopic characteristic of OMF of lateral pterygoid muscle.

Electronic Microphotography. Magnification: $a-4800 ; b, e-8000$;

$c, f-6400 ; d-12000$. Signs: 1 - extended endomysium, 2 - lumen of hemocapillary,

3 - dilated edematous perivascular space, 4 - mitochondria with preserved structure,

5 - vacuolated and destroyed mitochondria, 6 - dilated Z-line with blurred contours, 7 - nucleus of muscular fiber 
During the study of hemocapillaries there is a significant decrease of the number of capillaries in $1 \mu \mathrm{m}^{2}$, compared with the norm $(\mathrm{p}<0.001)$ (Fig. 2). There is also a marked decrease of the amount of haemocapillaries at one muscular fiber $(\mathrm{p}<0.01)$. During the electronic microscopic examination, there are significant edematous changes in endothelial cells (Fig. 12).

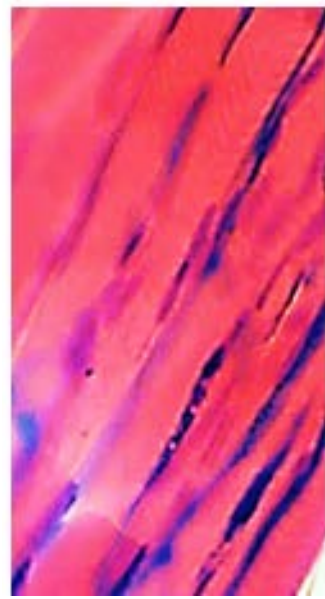

$a$

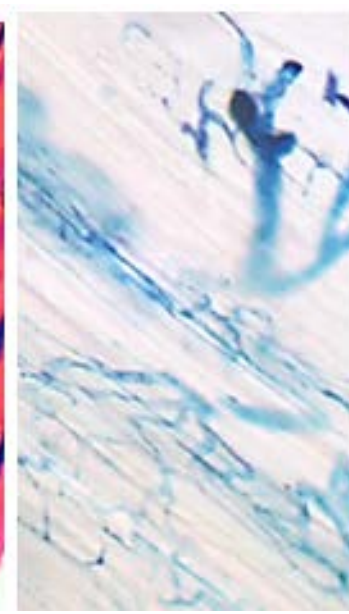

$b$

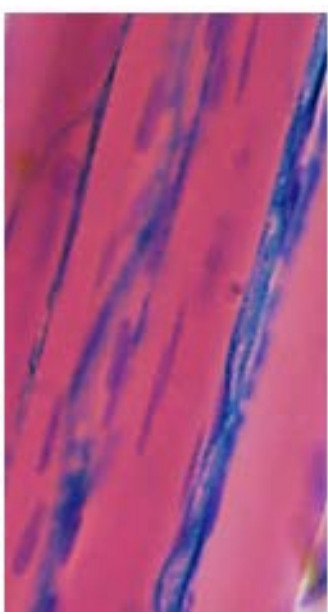

$c$

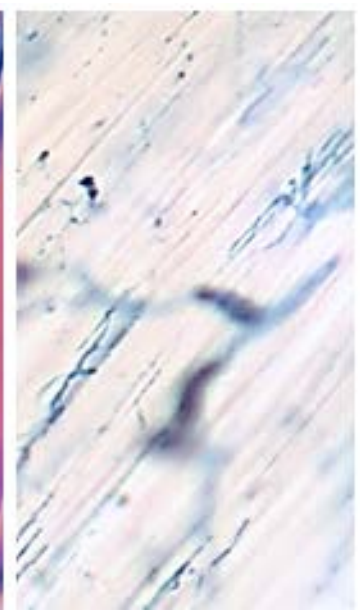

d

Fig. 11. Change of the vascular pattern of muscular fibers of the masticatory muscles of immature rats during the $21^{\text {st }}$ day of mercazolilum-induced hypothyroidism: $a$-changed vascular pattern in the masseter muscle; $b$-emptying of vessels in the masseter muscle; $c$-deformation of the vascular net in the lateral pterygoid muscle; $d$ - unevenness of the vascular pattern in the lateral pterygoid muscle. Staining: $a, c$-injection with Parisian blue with additional coloring of hematoxylinum and eosin; $b, d$-injection with Parisian blue. Microphotograph. Magnification: ocular lens 10 , field lens 20

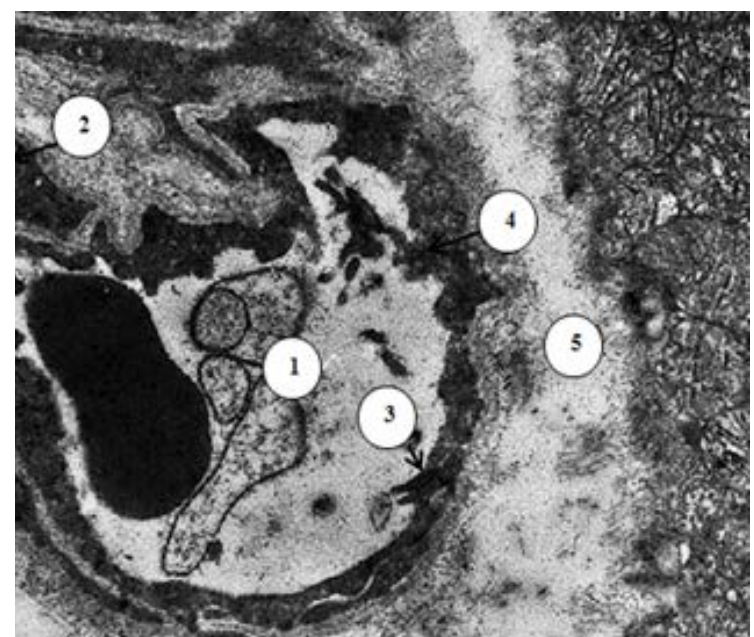

$a$

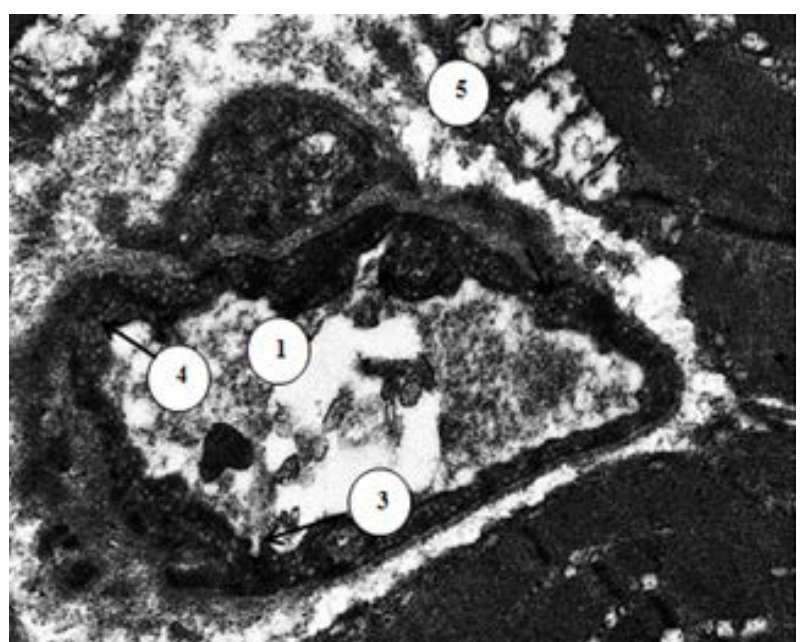

$b$

Fig. 12. Ultrastructure of the hemocapillary of the masticatory muscles of the immature rat during the $21^{\text {st }}$ day of the development of mercazolilum-induced hypothyroidism: $a$-submicroscopic structure of hemocapillary of masseter muscle; $b$ - changes in the hemocapillary of the lateral pterygoid muscle. Electronic Microphotography. Magnification: 8000. Signs: 1 - narrowed, deformed lumen of the hemocapillary, 2 - nucleus of the endothelyocyte, 3 - microclasmatosis, 4 - loose fibrous and dilated basal membrane of the hemocapillary; 5 - dilated and vacuolated perivascular space 
In all types of muscular fibers there are significant edematous changes, which are manifested by the increased light nucleus and loss of cross-striation of fibers, at the transverse sections - the fibers are of irregular round shape (Fig. 13). Some muscular fibers are dystrophically altered, they lose their cross-striation and have hyperchromic extracted nuclei in the form of dark "stripes". Between the fibers there is an expanded and vacuolated endomysium.

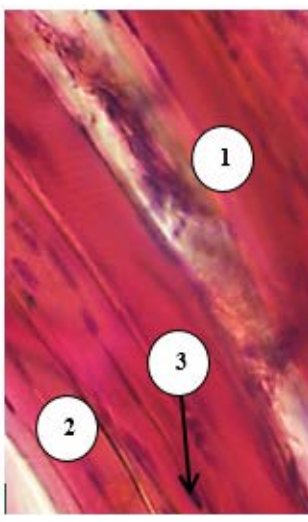

$a$

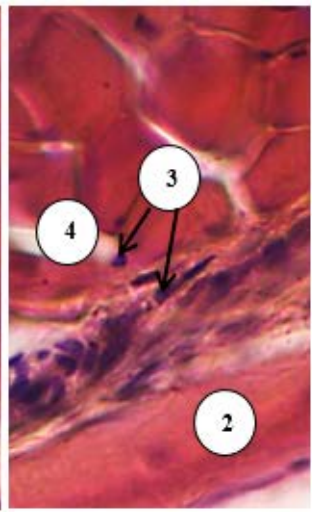

$b$

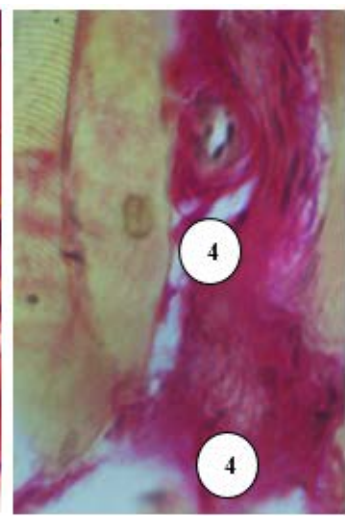

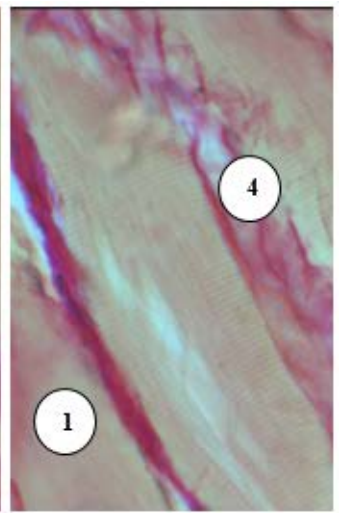

$d$

Fig. 13. Change of the structure of the masticatory muscles of immature rats during the $21^{\text {st }}$ day of experimental hypothyroidism: $a$-swelling and loss of cross-striation of muscular fibers in the masseter muscle; $b$-swelling and loss of cross-striation of muscular fibers in the lateral pterygoid muscle; $c$-swelling of the muscular fibers and extension of the endomysium in the masseter muscle; $d$-edema of muscular fibers and extension of endomysium in lateral pterygoid muscle. Staining: hematoxylin and eosin. Microphotograph. Magnification: ocular lens 10, field lens 40. Signs: 1 - loss of cross-striation of muscular fibers, 2 - edematous changes of muscular fibers, 3 - hyperchromatic nuclei of muscular fibers, 4 - dilation and edema of intermuscular layers

In the study of SDG-activity of muscular fibers, a further significant decrease of OGMF could be observed, comparing with the age-appropriate normal value. The number of GMF increased in this case (Fig. 7). The fibers are visually enlarged in size, unevenly filled with enzymes. Some of them are deformed (Fig. 14). Significantly increases the cross-striation area of all fibers (Fig. 8).

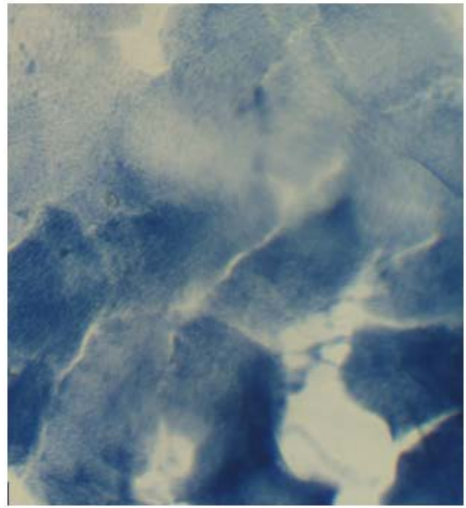

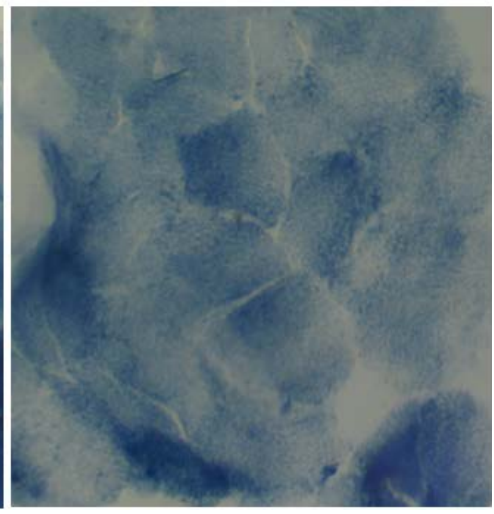

$b$

Fig. 14. Histochemical identification of muscular fibers of the masticatory muscles of immature animals during the $21^{\text {st }}$ day of experimental hypothyroidism: $a$ - swollen muscular fibers in the masseter muscle; $b$ - swollen muscular fibers in the lateral pterygoid muscle. Staining: succinate dehydrogenase according to M. Nachlas. Microphotograph. Magnification:

$a$ - ocular lens 10 , field lens 20, $b$ - ocular lens 10 , field lens 40 
In submicroscopic examination of the masseter and lateral pterygoid muscles, we have determined significant edematous changes of all types of muscular fibers that were surrounded by the same swollen stromal complex (Fig. 15).
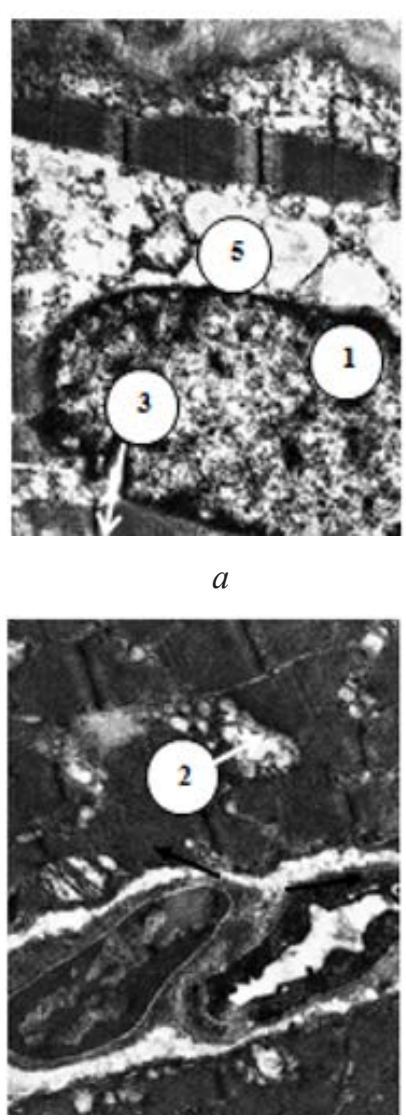

$d$

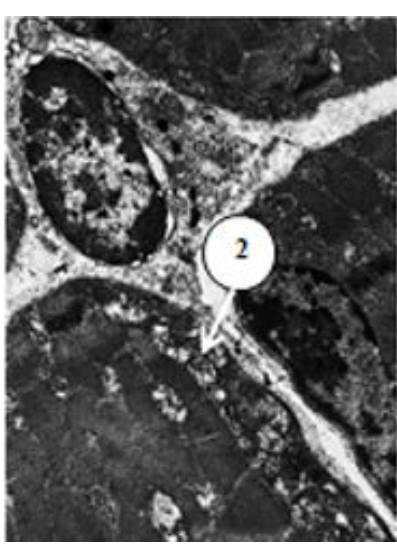

$b$

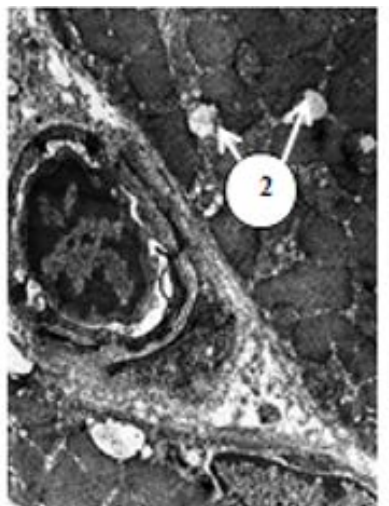

$e$

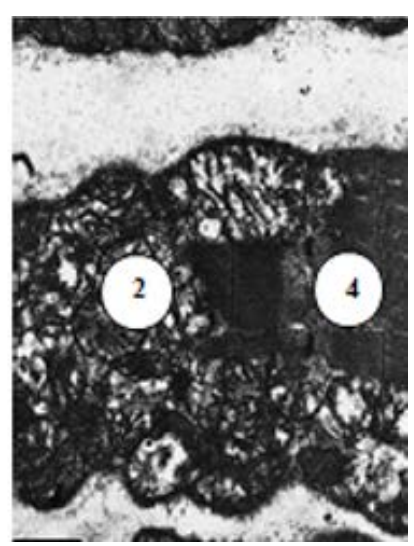

c

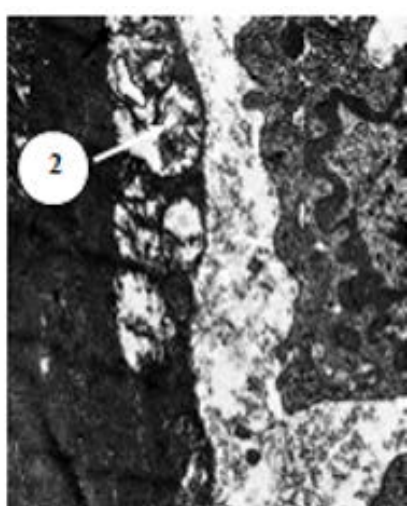

$f$

Fig. 15. Ultramicroscopic changes in the structure of the masticatory muscles of immature rat during the $21^{\text {st }}$ day of mercazolilum-induced hypothyroidism: $a$ - submicroscopic structure of GMF of masseter muscle;

$b$ - electron microscopic characteristic of OGMF of masseter muscle; $c$ - submicroscopic characteristic of OMF of masseter muscle; $d$-submicroscopic structure of the GMF of the lateral pterygoid muscle; $e$ - electron microscopic characteristic of OGMF of lateral pterygoid muscle; $f$ - submicroscopic characteristic of OMF of lateral pterygoid muscle. Electronic Microphotography. Magnification: $a, c-8000 ; b, e, f-64000 ; d-9600$. Signs: 1 - nucleus of nucleoplasm of reduced electronic density, 2 - vacuolated and destroyed mitochondria, 3 - dilated Z-line with blurred contours, 4 - fragment of "encapsulated" muscular fiber, 5 - optically lumenized round-nucleus area

Study of the vascular bed of masticatory muscles during the $28^{\text {th }}$ day of mercazolilum-induced hypothyroidism in the injection of Parisian blue has revealed a further decrease of the arterial diameter. In the light-optical study, it turns out that the vascular pattern loses its inherent spatial distribution, vessels are poorly injected, are unevenly filled with Parisian blue (Fig. 16). During the study of hemocapillaries there is a further significant decrease of their number, compared with the norm $(\mathrm{p}<0.0001)$ (Fig. 2).

During the electronic microscopic examination in endothelial cells, there is an edema and an increase of the nucleus. The cytoplasm is characterized by a decreased electronic density (Fig. 17). 


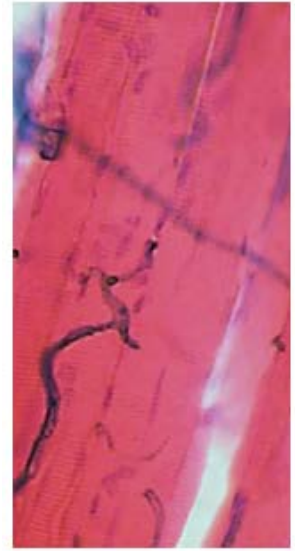

$a$

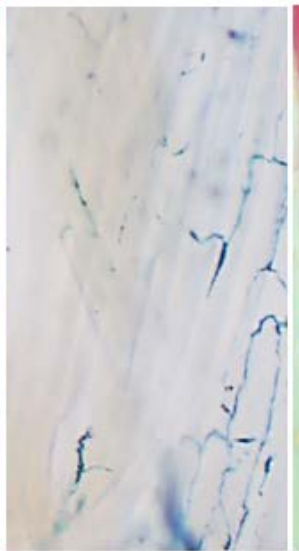

b

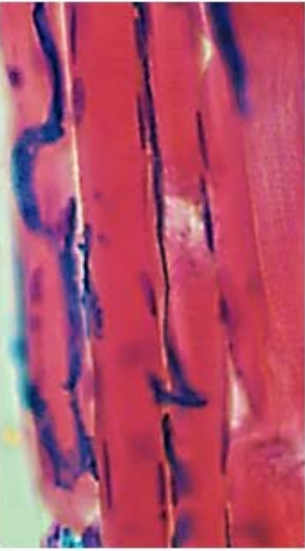

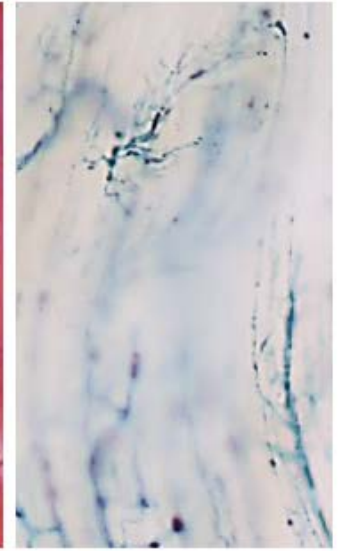

d

Fig. 16. Unevenness and desolation of the vascular pattern of muscular fibers of the masticatory muscles of immature rats during the $28^{\text {th }}$ day of mercazolilum-induced hypothyroidism: $a$-deformation of the vessel's bed of the masseter muscle; $b$ - emptying in the vessels of the masseter muscle; $c$-devastation and deformation of the vascular pattern; $d$ - unevenness of vascular filling in lateral pterygoid muscle. Staining: $a, c$ - injection with Parisian blue with additional coloring of hematoxylin and eosin; $b, d$-injection withParisian blue

In all types of muscular fibers there are significant edematous changes. The connective tissue of the endo- and perimysium is loose with optical cavities (Fig. 18). During the study of SDG-activity of muscular fibers, the uneven placement of the enzyme and subsequent reduction of OGMF can be observed (Fig. 7, 19). During the morphometric study in immature animals during the $28^{\text {th }}$ day of experimental hypothyroidism, the cross-striation area of all fibers is significantly increased relative to the control values and the previous experimental terms (Fig. 8).

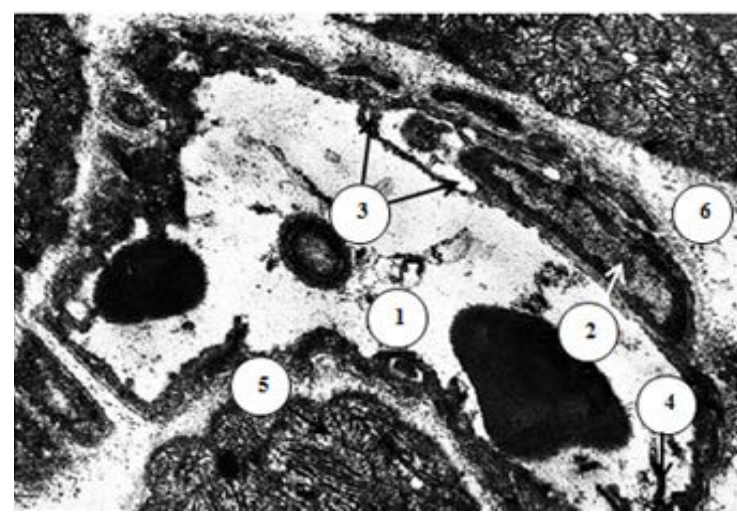

$a$

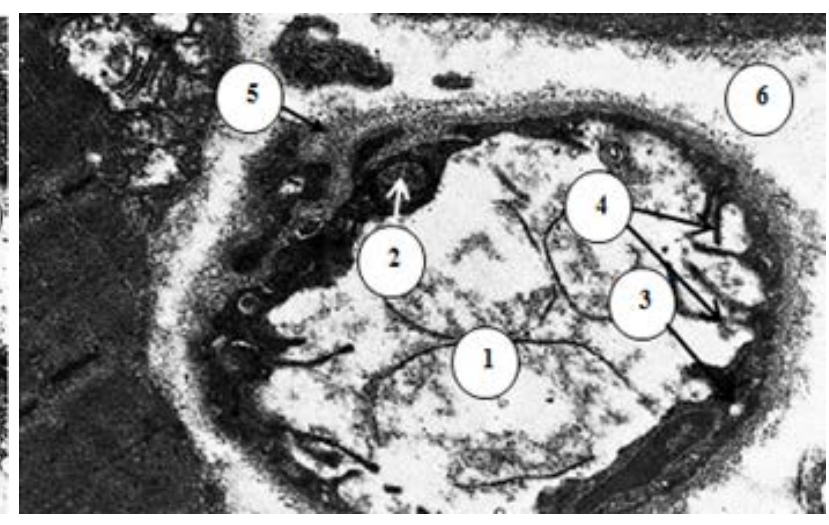

$b$

Fig. 17. Electronic microscopic changes in the structure of the hemocapillary of the masticatory muscles of the immature rat during the $28^{\text {th }}$ day of the development of mercazolilum-induced hypothyroidism: $a$-submicroscopic structure of hemocapillary of masseter muscle; $b$ - changes in the hemocapillary of the lateral pterygoid muscle. Electronic Microphotograph. Magnification:

$a-6400 ; b-8000$. Signs: 1 - deformed lumen of the hemocapillary, 2 - nucleus of the endothelial cell, 3 - vacuolization of the cytoplasm of the endothelial cell of hemocapillary, 4 - multiple microclasmatosis, 5 - loose fiber and dilated basal membrane of hemocapillary, 6 - expanded and vacuolated perivascular space

Submicroscopically, at this stage of our study, there were determined significant edematous changes of all types of muscular fibers with loss of cross-striation of myofibrils, dilation, blurring of Z-line, vacuolation of muscular triads, and destruction of the structure of mitochondria (Fig. 20). 


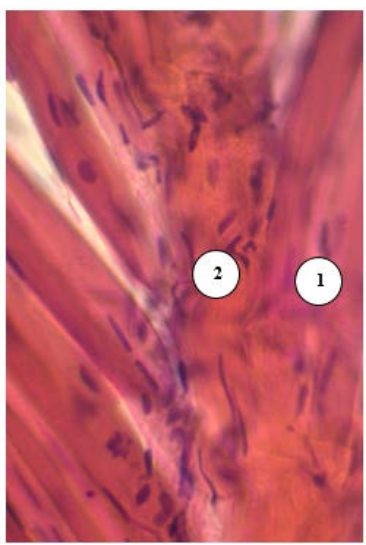

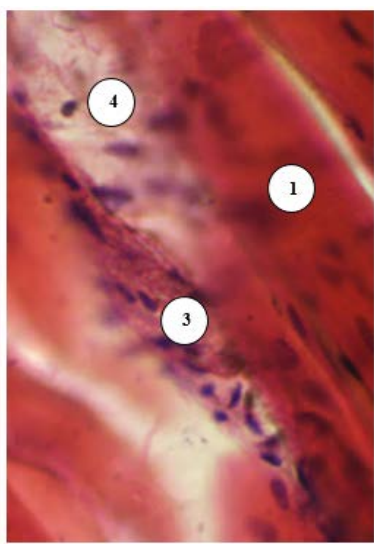

$b$

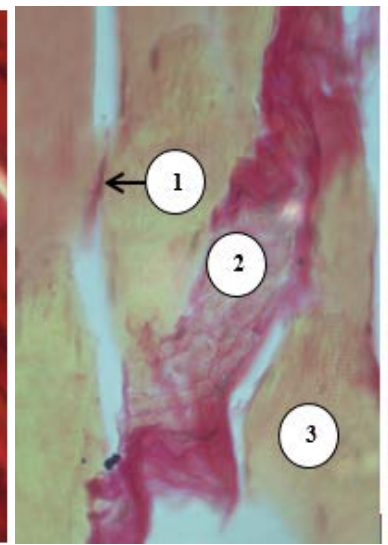

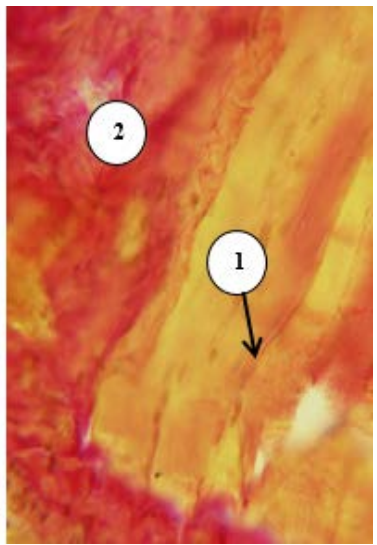

$d$

Fig. 18. Swelling of muscular fibers and endomysium of the masticatory muscles of immature rats during the $28^{\text {th }}$ day under the conditions of induced hypothyroidism: $a$-swelling and loss of cross-striation in the muscular fibers of the masseter muscle; $b$-edema and loss of cross-striation in the muscular fibers of the lateral pterygoid muscle; $c$-swellling and extension of the endomysium in the masseter muscle; $d$-swelling and enlargement of the endomysium in the lateral pterygoid muscle. Staining: $a, b$ - hematoxylin and eosin; $c, d$-hematoxylin-basic fuchsin-picric acid according to Van Gieson. Microphotograph. Magnification: ocular lens 10, field lens 40. Signs: 1 - edema and loss of cross-striation in muscular fibers, 2 - muscular fiber of "wave-shaped" form, 3 - dilated, with signs of edema, endomysium.

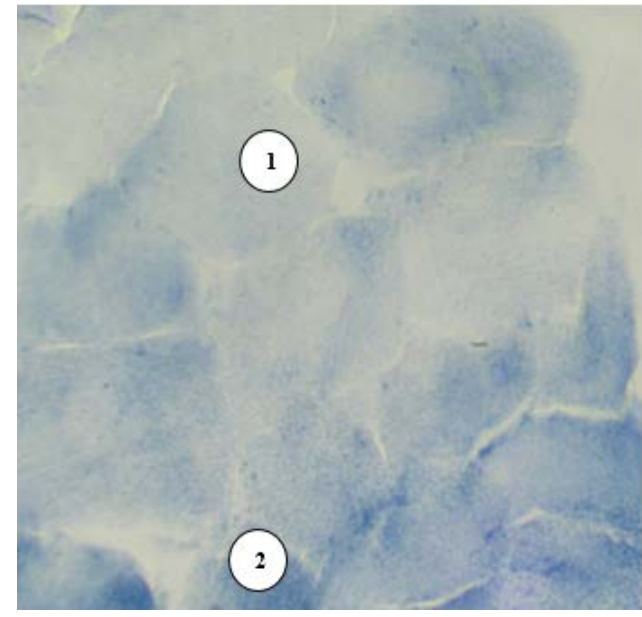

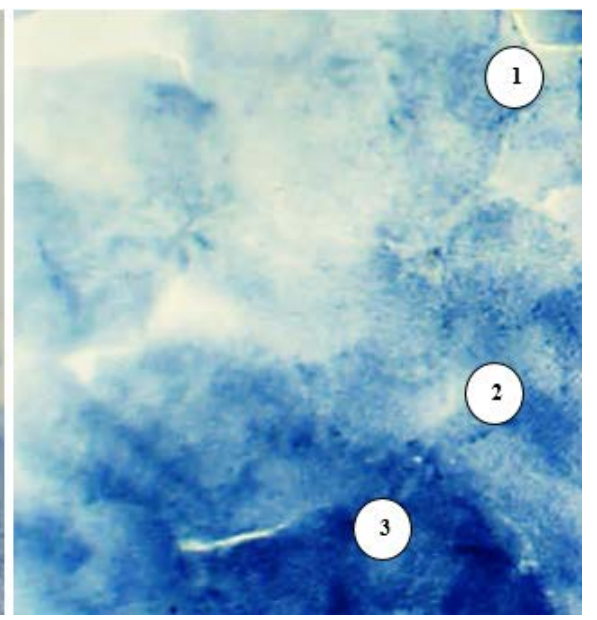

$b$

Fig. 19. Histochemical identification of the masticatory muscles of immature animals during the $28^{\text {th }}$ day of experimental hypothyroidism: $a$ - swollen muscular fibers in the masseter muscle;

$b$-swollen muscular fibers in the lateral pterygoid muscle. Staining: succinate hydrogenase according to M. Nachlas. Microphotograph. Stock: Magnification: ocular lens 10, field lens 20.

Signs: 1 - GMF, 2 - OGMF, 3 - OMF.

The morphological changes revealed by us are accompanied by violations of the macroelement balance, in particular the content of $\mathrm{Ca}, \mathrm{P}, \mathrm{Mg}$, which are determined by the functioning of skeletal muscular tissue [14]. Thus, during the $14^{\text {th }}$ day of the experiment, their content was $2.0 \pm 0.20 \mathrm{mmol} / \mathrm{l}(\mathrm{p}<0.01) ; 25.80 \pm 2.48 \mathrm{mmol} / \mathrm{l}(\mathrm{p}<0.01) ; 0.85 \pm 0.09 \mathrm{mmol} / \mathrm{l}(\mathrm{p}<0.01)$ respectively. During the $21^{\text {st }}$ day $-1.99 \pm 0.25 \mathrm{mmol} / 1(\mathrm{p}<0.01) ; 24.65 \pm 2.86 \mathrm{mmol} / \mathrm{l}(\mathrm{p}<0.01)$; $0.74 \pm 0.08 \mathrm{mmol} / \mathrm{l}(\mathrm{p}<0.01)$, during the $28^{\text {th }}$ day $-2.0 \pm 0.20 \mathrm{mmol} / \mathrm{l}(\mathrm{p}<0.01) ; 25.80 \pm 2.48 \mathrm{mmol} / 1$ $(\mathrm{p}<0.01) ; 0.85 \pm 0.09 \mathrm{mmol} / \mathrm{l}(\mathrm{p}<0.01)$ respectively. 


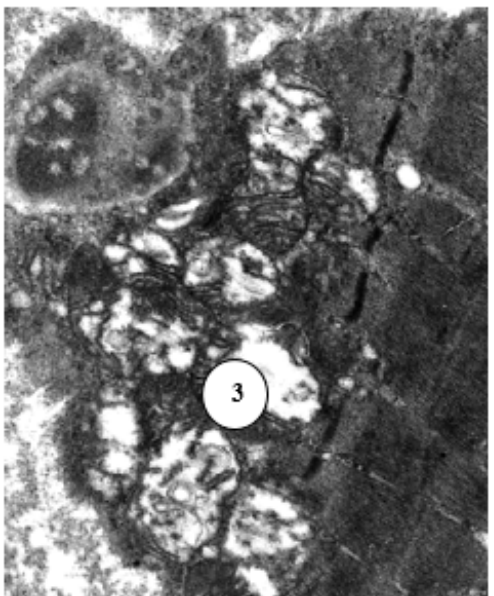

$a$

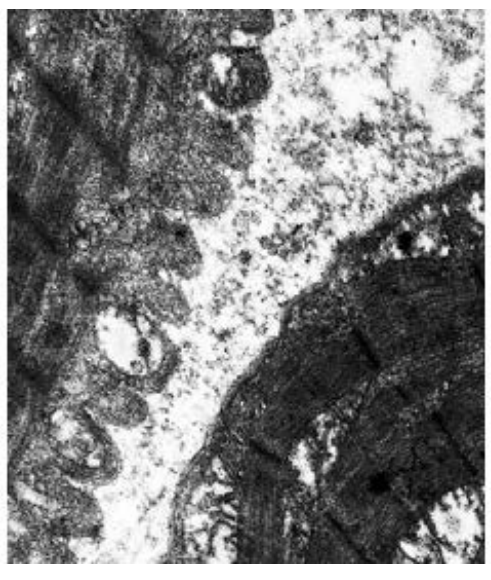

$d$

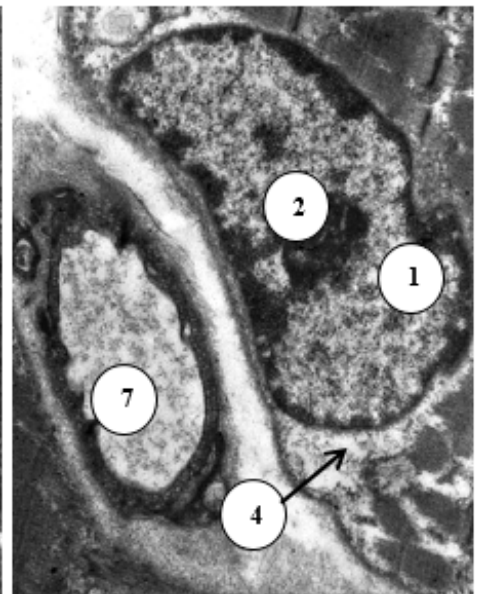

b

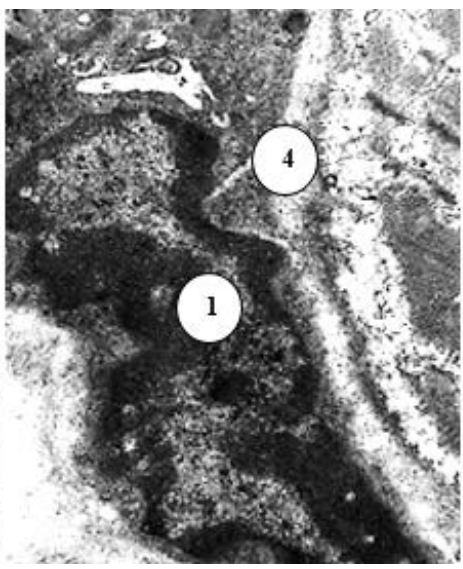

e

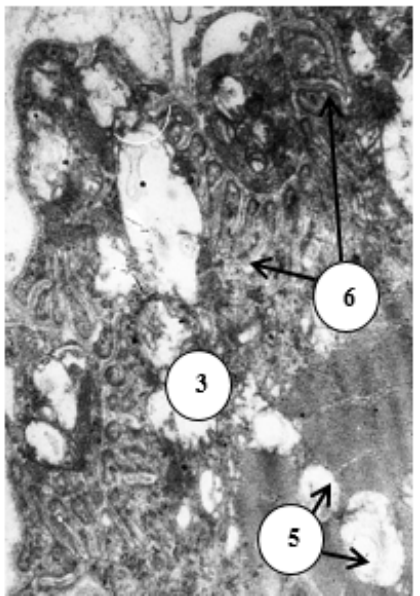

c

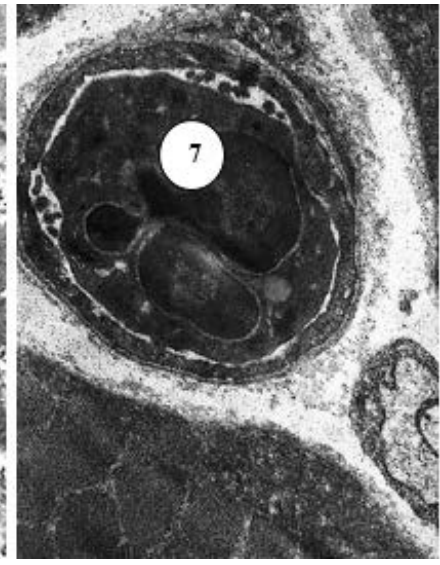

$f$

Fig. 20. Ultra-structural organization of the masticatory muscles of immature rat during the $28^{\text {th }}$ day of mercazolilum-induced hypothyroidism: $a$ - submicroscopic structure of GMF of masseter muscle; $b$ - electron microscopic characteristic of OGMF of masseter muscle;

$c$-submicroscopic characteristic of OMF of masseter muscle; $d$-submitcroscopic structure of the GMF of the lateral pterygoid muscle; $e$ - electron microscopic characteristic of OGMF of lateral pterygoid muscle; $f$-submicroscopic characteristic of OMF of lateral pterygoid muscle.

Electronic Microphotograph. Magnification: $a-9600 ; b, c, f-8000 ; d, e-12000$. Signs:

1 - nucleus of muscular fiber with marginally located heterochromatin, 2 - nucleolus, 3 vacuolated mitochondria, 4 - lumenized around nuclear space, 5 - vacuolated of muscular fibers, 6 - dilation and vacuolation of muscular triads, 7 - hemocapillary.

\section{Discussion}

In hypothyroidism in the vascular bed of masticatory muscles, there are already significant changes during the $14^{\text {th }}$ day, which is confirmed in the works [15] where the author claims that the most dangerous are the consequences for the development of hypothyroidism in the early stages of the body's formation - from the fetal period to puberty. Our results are consistent with studies of the vascular bed in hypothyroidism [16], where it was found that in patients with hypothyroidism there are sharply expressed violations in the system of terminal blood flow with the predominance of intravascular and vascular changes in the form of foci of microcongestion due to the increased blood viscosity, hematocrit, perivascular hemorrhages, perivascular edema, convulsivity of microvessels of all parts of the microcirculatory bed, and "sludge" - a phenomenon in the capillaries. Subsequently, during the $21^{\text {st }}$ and $28^{\text {th }}$ days of mercazolilum-induced hypothyroidism, we've observed a deepening of the vascular bed, which is consistent with studies [17], in which the 
morphological changes in the vascular bed of the experimental animals become more significant, with the continuation of the experiment time. Disorders in the vascular bed of masticatory muscles in hypothyroidism could be attributed to the development of endothelial dysfunction and violation of relaxation of smooth muscular cells in vessels, which leads to an increase in peripheral vascular resistance [18, 19]. In experimental mercazolilum-induced hypothyroidism, one can note the increasing edematous changes in all types of muscular fibers, and especially in glycolytic, which confirms the opinion that the severity of morphological changes in somatic muscles depends on the duration of hypothyroidism, and not on the severity and depth of the process [20,21]. Our studies are consistent with others, which found that fast muscle fibers are much more damaged than slow ones [22]. It is believed that this is due to the more subtle Z-and M-discs. In the structure of muscular fibers, loss of cross-striation and mosaic structure could be observed. These changes in fibers could be found in the works of other scholars [23], which they explain as "focal lysis", associated with damage to lysosomes and the activation of acidic hydrolases. This pathology occurs, mainly in hypoxic conditions. Significant edema could be observed in the connective tissue components of the endo- and perimysium, the diffuse accumulation of glycoproteins, which is the determining factor of exudation and leads to an increase of muscular fibers, not to the muscular strength, but on the contrary to the development of muscular hypotension [24]. Reduction of muscular strength of skeletal muscles in hypothyroidism, could be possibly due to the direct influence of $\mathrm{T}_{4}$ on the structural-functional characteristics of membranes, including the membrane of the sarcoplasmic reticulum. In this case, both lipid and protein component of the "liquid" bilayer is changing. This reduces the activity of $\mathrm{Ca}^{2+}$ - ATPase and decreases the rate of absorption of calcium ions [25]. Changes in muscles in hypothyroid myopathy are characterized by their increase and consolidation. We've also found ultramicroscopic changes in all types of muscular fibers. Similar changes occur in the tooth-jaw system (mucous gum membrane, periodontium, jawbone tissue, tooth pulp) in experimental hypothyroidism, in fact: dystrophic, atrophic and destructive changes in parenchymal structures and miksedematous edema of stroma [24]. The described changes are caused by a decrease in the level of the main metabolism, the retardation of oxidative-reducing processes and, as a consequence, tissue hypoxia. Inflammation severity was characterized by inflammatory polymorphic-cell infiltrate with a high content of neutrophil granulocytes, as well as an exudative component that occurs as a result of glycoprotein accumulation in tissues. In this case, chromotropic substances are released from the bonds with proteins and accumulate mainly in the intermediate tissue, followed by the replacement of collagenous fibers with mucus-shaped masses. Infiltrate accumulates in large quantities in the intermediate tissue, as a result there is a compression of cells, dystrophy, necrobiosis, necrosis and atrophy.

\section{Conclusions}

1. In the conditions of experimental hypothyroidism in the masticatory muscles of immature rats, morphofunctional developing changes are complicated in the dynamics of hypothyroidism. Initial manifestations were discovered during the $14^{\text {th }}$ day, the detailed picture - during the $21^{\text {st }}$ day, and during the $28^{\text {th }}$ day in all investigated structures the severe structural changes with necrosis were found.

2. In experimental hypothyroidism in different terms, we have observed the deepening of changes in both the arterial and venous channels. And the damage was significant regardless of the age and functionality of the muscle. These changes are characterized by a significant decrease of the lumen of the arteries and arterioles, some of them are generally closed. There is a thickening of the arterial wall with structural violation and edematous changes. At the same time, the lumen of the veins and venules extends, their walls deform and become thinned. Particularly the links of the hemomicrocirculatory bed are affected.

3. In muscular fibers in hypothyroidism there are significant edematous changes both in histological and ultrastructural levels. Glycolytic muscular fibers, especially in immature animals, are more likely to suffer. Swelling and vacuolation of the connective tissue of the endomysium and perimysium are also noted. Moreover, the changes are deepened depending on the duration of the experiment. 


\section{References}

[1] Bodnar, P. M. (2010). Endocrinology. Vynnytsia: Nova knyha, 464.

[2] Denga, O. V., Kolesnik, K. A. (2012). The role of thyroid hormones in the integral regulation of bone metabolism in norm and in hypothyroidism (review of literature). Tavricheskiy mediko-biologicheskiy vestnik, 1, 332-337.

[3] Danilov, N. V. (2014). Osteoporosis as a problem of thyroid surgery (literature review). Nauka molodykh, 1, 105-113.

[4] Egorova, E. N., Vavilova, T. V., Ivanov, A. M., Kharitonov, M. A., Kalinina, N. L., Tatarkin, A. A. (2013). Study of hemostasis system parameters in patients with hypothyroidism. Saint Petersburg, 57-58.

[5] Kovrigina, T. R., Filimonov, V. I. (2010). Differentiation of skeletal muscles of the shin in the postnatal period of ontogenesis. Morfologiya, 137 (3), 36-40.

[6] Tambovtseva, R. V. (2014). Biochemical peculiarities of the ontogenetic development of energy supply of muscular activity. Novyye issledovaniya, 1, 68-75.

[7] Bagarian, E. A., Lepilin, A. V., Konnov, V. V., Batusov, O. N. (2011). Changes in the function of the masticatory muscles in patients with mandibular fractures. Razvitiye stomatologicheskoy nauki i praktiki. Poltava, 61-62.

[8] Bezzubenkova, O. E., Kurnosova, O. N. (2010). The consistency of food as a physical factor in the regulation of morphogenesis of the muscles of the jaw apparatus of rats. Morfologicheskiye vedomosti, $4,15-24$.

[9] Kulimbetov, M. T., Rashitov, M. M., Saatov, T. S. (2009). Simulation of experimental hypothyroidism due to natural chronic iodine deficiency in the diet. International Endocrinological Journal, 2 (20), 22-27.

[10] Charnosh, S. M. (2007). The comparative characteristic of three experimental models of hypothyroidism. Visnyk naukovykh doslidzhen, 2, 113-115.

[11] Atamanchuk, O. V. (2012). Morphofunctional changes of tongue in experimental diabetes mellitus. Galician Medicinal Herald, 19 (4), 9-11.

[12] Goncharov, N. P. (2011). Modern methods of hormonal analysis. Problems of Endocrinology, 57 (1), 86-91. doi: http://doi.org/10.14341/probl201157186-91

[13] Cardoso, L. F., Maciel, L. M. Z., de Paula, F. J. A. (2014). The multiple effects of thyroid disorders on bone and mineral metabolism. Arquivos Brasileiros de Endocrinologia \& Metabologia, 58 (5), 452-463. doi: http://doi.org/10.1590/0004-2730000003311

[14] Bodnar, P. M., Mykhalchyshyn, H. P. (2010). Iodine deficiency diseases and their prophylaxis. International Endocrinological Journal, 4 (6), 46-48.

[15] Kaminsky, A. V., Tatarchuk, T. F. (2017). Hypothyroidism and pregnancy: new recommendations on the peculiarities of diagnosis and treatment tactics. International Endocrinological Journal, 2, 152-157.

[16] Kozlova, L. K., Kuchma, G. B., Turmukhambetova, B. T., Ibragimova, E. A., Sokolova, N. V., Shatilov, A. P. (2017). Complex disorders of heart rhythm and conductivity in a patient with hypothyroidism (clinical observation). Archive of Internal Medicine, 7 (6), 462-468. doi: http://doi.org/10.20514/2226-67042017-7-6-462-468

[17] Dolbin, I. V., Ekimovskikh, A. Y. (2016). Hypothyroidism and ischemic cardiac disease: modern condition of the issue. Medical Almanac, 4, 121-126. doi: http://doi.org/10.21145/2499-9954-2016-4-121-126

[18] Habersberger, J., Eisenhardt, S., Peter, K. (2010). C-reactive protein measurement and cardiovascular disease. The Lancet, 375 (9720), 1078. doi: http://doi.org/10.1016/s0140-6736(10)60470-9

[19] Hernández-Mijares, A., Jover, A., Bellod, L., Bañuls, C., Solá, E., Veses, S. et. al. (2013). Relation between lipoprotein subfractions and TSH levels in the cardiovascular risk among women with subclinical hypothyroidism. Clinical Endocrinology, 78 (5), 777-782. doi: http://doi.org/10.1111/cen.12064

[20] Jiskra, J. (2001). Changes in muscle tissue in hypothyroidism. Vnitr. Lek., 47 (9), 609-612.

[21] Madariaga, M. G., Gamarra, N., Dempsey, S., Barsano, C. P. (2002). Polymyositis-Like Syndrome in Hypothyroidism: Review of Cases Reported Over the Past Twenty-Five Years. Thyroid, 12 (4), 331-336. doi: http://doi.org/10.1089/10507250252949478

[22] Samsonova, A. V., Barnikova, I. E., Borisevich, M. A., Vakhnin, A. V. (2012). Methods for assessing the composition of muscle fibers in human skeletal muscles. Proceedings of the Department of Biomechanics NSU named after P. F. Lesgaft, 6, 18-27. 
[23] Sorokina, O. N. (2004). The state of masticatory muscles in modeling the mandibular deformity during the period of its active growth. Novosibirsk, 23.

[24] Murphy, E., Williams, G. R. (2004). The thyroid and the skeleton. Clinical Endocrinology, 61 (3), 285-298. doi: http://doi.org/10.1111/j.1365-2265.2004.02053.x

[25] Mi, Y. F., Li, X. Y., Tang, L. J. (2009). Improvement in cardiac function after sarcoplasmic reticulum $\mathrm{Ca}^{2+}$ ATPase gene transfer in a beagle heart failure model. Chinese Medical Journal, 122 (12), $1423-1428$.

\title{
MEDICAL GENETIC COUNSELING OF WOMEN WITH CONGENITAL HEART DISEASES OF FETUS
}

\author{
Yevheniya Sharhorodska \\ Department of Clinical Genetics \\ Institute of Hereditary Pathology of the National Academy of Medical Sciences of Ukraine \\ 31 A Lysenko str., Lviv, Ukraine, 79008 \\ gendoctor86@gmail.com \\ Nadiya Helner \\ Medical genetic center \\ Institute of Hereditary Pathology of the National Academy of Medical Sciences of Ukraine \\ 31 A Lysenko str., Lviv, Ukraine, 79008 \\ Natalia Prokopchuk \\ Medical genetic center \\ Institute of Hereditary Pathology of the National Academy of Medical Sciences of Ukraine \\ 31 A Lysenko str., Lviv, Ukraine, 79008 \\ prokopchuk-natalia@ukr.net \\ Halyna Makukh \\ Genetic laboratory \\ Institute of Hereditary Pathology of the National Academy of Medical Sciences of Ukraine \\ 31 A Lysenko str., Lviv, Ukraine, 79008 \\ makukh_halyna@ukr.net
}

\begin{abstract}
Aim of the work. Determine the effectiveness of prenatal diagnosis of congenital heart defects in the fetus and the informativeness of different markers used in the medical-genetic counseling of pregnant women..

Materials and methods. The analysis of the results of medical genetic counseling of pregnant women with fetal heart diseases was carried out. The effectiveness of using different methods of prenatal diagnosis in 67 pregnant women is estimated. The data of somatic, genealogical and reproductive anamnesis, biochemical markers of chromosomal pathology of the 1st and 2nd trimester of pregnancy, and the spectrum of the detected fetal heart disease were studied.

Results of the research. It was found that $46(68.7 \%)$ women had somatic diseases: pathology of the cardiovascular system $(11.9 \%)$; endocrine system - at 8 (11,9\%); respiratory disease - $3(4.5 \%)$ and urinary system - $2(3.0 \%) .13(19.4 \%)$ out of 67 women had acute respiratory viral infections in the first trimester of pregnancy. In 4 (6\%) cases - bad habits. The first time pregnant were $31(46.3 \%)$ women, $21(31.3 \%)$ - the second time, $10(14.9 \%)$ in the third, and $5(7.5 \%)$ in the fourth or more times. In history, $58(86.6 \%)$ women did not have reproductive function disorders, $8(11.9 \%)$ had unauthorized miscarriages and frozen pregnancy. The burden of gynecological anamnesis was observed in 12 (17.9\%) women, and hereditary - in 6 ( $9.0 \%)$ women. In the structure of congenital defects of the heart, false anatomical anomalies were found more often: hypoplasia of the left heart organs - 14 (20.9\%), tetralogy of Fallot - 9 (13.3\%). Biochemical markers of chromosomal pathology in the first trimester in $11(16.4 \%)$ women recorded indicators that are characteristic of the risk of chromosomal pathology, and in the second trimester - in 9 (13.4\%). Two pregnant women used a NIPT (non-invasive prenatal test) test that did not detect chro-
\end{abstract}

